\title{
Limited role for nitric oxide in mediating cerebrovascular control of newborn piglets
}

\author{
J Patel, O Pryds, I Roberts, D Harris, A D Edwards
}

\begin{abstract}
Aims-To investigate the effects of the nitric oxide (NO) synthase inhibitor L-nitro-arginine methyl ester (L-NAME) on cerebral blood flow, and its response to alterations in arterial carbon dioxide tension (CBF- $\mathrm{CO}_{2}$ reactivity).

Methods-Cerebral blood flow was measured six times at varying arterial carbon dioxide tension $\left(\mathrm{PaCO}_{2}\right)$ using the intravenous ${ }^{133} \mathrm{Xenon}$ clearance technique in eight mechanically ventilated piglets of less than 24 hours postnatal age. After the third measurement L-NAME was administered as a bolus ( $20 \mathrm{mg} / \mathrm{kg}$ ) and subsequently infused (10 mg/kg/hour).

Results- $\mathrm{PaCO}_{2}$ ranged between 2.7-8.9

kPa. Cerebral blood flow decreased by $14.0 \%$ (95\% confidence interval 1.9-27.4) after L-NAME. CBF-CO $\mathrm{C}_{2}$ reactivity was $18.4 \%$ per $\mathrm{kPa}(95 \%$ CI 14.1-22.2) before L-NAME and $15.2 \% / \mathrm{kPa}(95 \%$ CI 11.1 19.3) afterwards; the difference between the $\mathrm{CBF}-\mathrm{CO}_{2}$ reactivities was $3.2 \% / \mathrm{kPa}$ (95\% CI -0.4-6.8): these were not significantly different.

Conclusions-Inhibition of nitric oxide synthesis reduces cerebral blood flow no more than a 0.5-1.0 $\mathrm{kPa}$ fall in $\mathrm{PaCO}_{2}$. Nitric oxide is not an important mediator of $\mathrm{CBF}-\mathrm{CO}_{2}$ reactivity. (Arch Dis Child 1996;75:F82-F86)
\end{abstract}

Keywords: L-nitro-arginine methyl ester, cerebral blood flow, carbon dioxide reactivity, ${ }^{133}$ Xenon clearance.

Royal Postgraduate Medical School, Hammersmith

Hospital, London

J Patel

I Roberts

A D Edwards

Department of

Anaesthesia

D Harris

Department of

Paediatrics and

Neonatal Medicine,

Rigshospitalet,

Copenhagen, Denmark

O Pryds

Correspondence to:

Dr Ole Pryds, Department of

Neonatology, State

University Hospital,

Brendstrupgardsvej, 8200

Arhus N, Denmark.

Accepted 17 May 1996 mediators such as prostaglandins may have greater role in controlling cerebrovascular responses in the newborn. ${ }^{10} 11$ le on its role in the cerebral cir during the perinatal period. Importan

Disruption of cerebral blood flow is implicated in the cerebrovascular control of adult tion to its physiological properties, excessi NO generation following cerebral ischaemia may contribute significantly to neuronal injury. ${ }^{7-9}$ However, comparatively few data are rhagic brain injury in the perinatal period, leading to long term neurodevelopmental
sequelae. ${ }^{12}$ Therefore, further information on its control is required if therapeutic interventions to improve cerebral injury are to be developed.

Nitric oxide (NO) is an important mediator mals, ${ }^{34}$ and has been strongly implicated in the in the cerebrovascular control of adult a
In a previous study inhibition of NO synthesis by competitive inhibition of the enzyme nitric oxide synthase (NOS) with the L-arginine analogue, L-NAME, caused cerebral vasoconstriction, as shown by a small fall in cerebral blood volume (CBV). ${ }^{12}$ However, L-NAME had no effect on the response of CBV to changes in $\mathrm{PaCO}_{2}$, also suggesting significant differences between neonatal and adult cerebrovascular control. In that study it was not possible to determine whether the vasoconstriction induced by L-NAME affected resistance vessels, and thus cerebral perfusion, or whether the fall in CBV was due to alterations in venous capacitance vessels. Equally, studies of the adult brain have used $\mathrm{CBF}-\mathrm{CO}_{2}$ as a measure of the cerebrovascular response to changes in $\mathrm{PaCO}_{2}$, which have made it difficult to compare directly the results of neonatal and adult studies.

The aim of the present study was to quantitate the effects of NOS inhibition on cerebral blood flow and $\mathrm{CBF}-\mathrm{CO}_{2}$ reactivity in newborn piglets using the intravenous ${ }^{133}$ Xenon technique. We tested the null hypothesis that these parameters remain unaffected following the administration of L-NAME.

\section{Methods}

Eight Large White piglets born at 113-117 (median 115) days after conception and weighing 1.30-2.00 (median 1.60) $\mathrm{kg}$ were studied on the first day of life. After premedication with intramuscular midazolam $(0.20$ $\mathrm{mg} / \mathrm{kg}$ ) anaesthesia was induced and maintained with inhaled isoflurane (0.7-1.2\%). Core body temperature was maintained by heating lamps at between 38 and $39^{\circ} \mathrm{C}$, within the normal range for newborn piglets. Subjects were given a tracheotomy and mechanically ventilated using a pressure limited ventilator (SLE 2000, Surrey, UK) with an inspiratory time of 0.5 seconds, a peak inspiratory pressure of 1.3-1.8 kPa, an initial ventilatory rate of 30 breaths/minute, and an inspired gas mixture of oxygen, air, and isoflurane that was sufficient to maintain light anaesthesia and permit manipulation of arterial blood gases.

An ear vein was cannulated and glucose $10 \%$ was infused at 5-7 ml/hour to provide blood glucose concentrations of $\geqslant 4 \mathrm{mmol} / \mathrm{l}$ (BMstix, Boehringer Mannheim, Germany). An umbilical venous catheter (5.0F) was placed for central venous access and infused with $10 \%$ dextrose containing $1 \mathrm{IU}$ of heparin/ml at $1 \mathrm{ml} /$ hour. An umbilical arterial catheter $(3.5 \mathrm{~F})$ was sited for arterial access and infused with $0.9 \%$ saline containing 1 IUof heparin/ml at $1 \mathrm{ml}$ 
Table 1 Physiological variables before each measurement of cerebral blood flow

\begin{tabular}{|c|c|c|c|c|c|c|c|c|c|c|c|c|}
\hline \multirow[b]{2}{*}{ Parameter } & \multicolumn{6}{|c|}{ Before $L-N A M E$} & \multicolumn{6}{|c|}{ After $L-N A M E$} \\
\hline & 1 & & 2 & & 3 & & 1 & & 2 & & 3 & \\
\hline $\begin{array}{l}\text { Arterial pressure (mm } \\
\mathrm{Hg} \text { ) }\end{array}$ & 58.0 & (6.5) & 60.8 & $(7.9)$ & 65.0 & (8.9) & 75.4 & $(8.8)^{\star}$ & 75.5 & $(10.5)^{\star}$ & 73.6 & $(9.6)^{\star}$ \\
\hline Core temperature $\left({ }^{\circ} \mathrm{C}\right)$ & 38.0 & $(0.9)$ & 38.0 & $(0.9)$ & 38.3 & $(0.9)$ & 38.3 & $(0.8)$ & 38.4 & $(0.8)$ & 38.1 & $(0.7)$ \\
\hline Arterial pH & 7.49 & $(0.05)$ & 7.49 & $(0.10)$ & 7.53 & $(0.16)$ & 7.47 & $(0.17)$ & 7.45 & $5(0.10)$ & 7.40 & $(0.10)$ \\
\hline $\mathrm{PaO}_{2}(\mathrm{kPa})$ & 17.2 & $(4.6)$ & 19.4 & $(6.0)$ & 16.9 & $(6.4)$ & 19.5 & $(6.1)$ & 21.6 & $(9.1)$ & 19.9 & $(7.7)$ \\
\hline $\mathrm{PaCO}_{2}(\mathrm{kPa})$ & 5.2 & (1.2) & 5.3 & (1.8) & 4.8 & (1.6) & 4.9 & $(2.2)$ & 5.1 & $(1.4)$ & 5.8 & $(2.1)$ \\
\hline Base excess $(\mathrm{mmol} / \mathrm{l})$ & 3.0 & (1.9) & 5.7 & (2.9) & 4.2 & (4.9) & 2.7 & (2.3) & 1.7 & (3.0) & 2.6 & $(2.2)$ \\
\hline Haemoglobin $(\mathrm{g} / \mathrm{dl})$ & 8.8 & (1.3) & 9.3 & (1.4) & 9.3 & (1.5) & 10.0 & (1.7) & 10.2 & (1.7) & 9.9 & (1.8) \\
\hline Blood glucose $(\mathrm{mmol} / \mathrm{l})$ & 5.6 & (2.3) & 6.3 & (2.5) & 6.4 & $(2.1)$ & 7.0 & $(2.1)$ & 6.8 & $(1.9)$ & 7.0 & $(2.1)$ \\
\hline
\end{tabular}

Values are mead (SD). For all values $n=8$ animals. Cerebral blood flow measured on six occasions; three measurements before the administration of L-NAME and three afterwards.

* Arterial pressure was significantly different after administration of L-NAME $(P<0.005)$.

hour. Mean arterial blood pressure (MAP) was recorded directly from the umbilical arterial catheter using a pressure transducer (Statham, California, USA). End-tidal partial pressure of carbon dioxide $\left(\mathrm{PCO}_{2}\right)$ was monitored throughout the study (Capnomac II, Datex, Helsinki, Finland) only to confirm that $\mathrm{PaCO}_{2}$ remained stable at the set concentration; frequent blood gas analysis was performed on umbilical arterial blood samples (ABL 3, Radiometer, Copenhagen, Denmark) to obtain absolute values for $\mathrm{PaCO}_{2}$.

MEASUREMENT OF CEREBRAL BLOOD FLOW Cerebral blood flow was determined using the intravenous ${ }^{133}$ Xenon technique, as described before. ${ }^{1{ }^{13}}$ Xenon $(40-60 \mathrm{mBq} / \mathrm{kg})$ was injected into the umbilical venous catheter, and the activity recorded by scintillators (Simonsen Medical A/S, Randers, Denmark) placed over the left parieto-temporal region and the thorax. Before each of the cerebral blood flow measurements, the background activity was measured for 0.5 or 5 minutes and accounted for in the subsequent calculation.

Cerebral ${ }^{133}$ Xenon clearance was determined for 11 minutes, starting from the time when the activity in the lung had decreased to $20 \%$ of the peak activity. This level was used to reduce the effect of scattering from the airways. CBF was calculated using the Obrist 2 compartment analysis, and adjusted for the haemoglobin concentration. ${ }^{14}$ The blood-brain partition coefficients for grey and white matter, derived from studies on adult human brain, were assumed to be 0.8 and 1.5 , respectively. ${ }^{14} \mathrm{CBF}$ represents the weighted mean of cerebral grey and white matter blood flow, ${ }^{15}$ is considered to represent global cerebral blood flow, and is presented as $\mathrm{ml} / 100 \mathrm{~g} /$ minute. The test-retest variation in cerebral blood flow measurements is $10.7 \% .^{16}$

EXPERIMENTAL PROTOCOL

A period of stabilisation lasting at least $75 \mathrm{~min}$ utes was allowed following subject preparation. A total of six measurements of cerebral blood flow were then performed in each animal at different concentrations of $\mathrm{PaCO}_{2} \cdot \mathrm{PaCO}_{2}$ was manipulated within or close to the physiological range, at random, by changing the ventilatory rate or by introducing an extra dead space, as appropriate. A stabilisation period of 20 minutes was allowed following each attempted manipulation of $\mathrm{PaCO}_{2}$. The ventilation was not manipulated between the third and fourth measurements. $\mathrm{FIO}_{2}$ was adjusted, aiming to keep arterial oxygen tension $\left(\mathrm{PaO}_{2}\right)$ at $\geqslant 13.0$ $\mathrm{kPa}$. After the third measurement of cerebral blood flow L-NAME was administered as a bolus $(20 \mathrm{mg} / \mathrm{kg})$ and was subsequently infused in $10 \%$ glucose at a rate of 10 $\mathrm{mg} / \mathrm{kg} /$ hour through the peripheral venous cannula. This dosage of L-NAME has been found to have near maximal effect on the cerebral vasculature of newborn piglets. ${ }^{12}$ Cerebral blood flow measurements were restarted 20 minutes after administration of the L-NAME bolus. Finally, L-arginine was administered as an intravenous bolus (1g) to reverse NOS inhibition, and the effects on MAP were observed.

At the end of the experiment, subjects were sacrificed by an overdose of pentobarbital. Experiments were carried out under license from the Home Office and according to United Kingdom guidelines.

STATISTICAL ANALYSIS

The null hypotheses tested were that cerebral blood flow and $\mathrm{CBF}-\mathrm{CO}_{2}$ reactivity remain constant after administration of L-NAME. A calculation of study power using previous data, which estimated the intrasubject coefficient of variation as between $8 \%$ and $17 \%$, revealed that a minimum of eight piglets should be investigated to detect an effect of L-NAME on the cerebral blood flow of at least $15 \%(\alpha=0.05$ and $\beta \geqslant 0.90$ ). Inspection of data distributions showed that cerebral blood flow values were positively skewed and the data were therefore transformed logarithmically to obtain homogeneity of variance, thus assuming a log-linear relation between cerebral blood flow and $\mathrm{PaCO}_{2}$. The regression analysis was performed

Table 2 Arterial carbon dioxide tension for individual piglets before each measurement of cerebral blood flow

\begin{tabular}{|c|c|c|c|c|c|c|}
\hline \multirow[b]{3}{*}{ Piglets } & \multicolumn{6}{|c|}{$\mathrm{PaCO}_{2}(\mathrm{kPa})$} \\
\hline & \multicolumn{3}{|c|}{ Before $L-N A M E$} & \multicolumn{3}{|c|}{ After $L-N A M E$} \\
\hline & 1 & 2 & 3 & 1 & 2 & 3 \\
\hline 1 & 4.5 & 6.5 & 2.9 & 2.7 & 4.9 & 5.7 \\
\hline 2 & 4.4 & 4.8 & 6.1 & 4.1 & 5.4 & 5.9 \\
\hline 3 & 5.3 & 3.6 & 5.2 & 6.3 & 4.6 & 3.7 \\
\hline 4 & 4.4 & 3.3 & 7.5 & 8.2 & 4.8 & 3.5 \\
\hline 5 & 4.9 & 3.6 & 5.8 & 7.6 & 3.3 & 4.5 \\
\hline 6 & 5.3 & 6.6 & 3.4 & 3.3 & 5.0 & 8.8 \\
\hline 7 & 4.5 & 8.5 & 3.8 & 3.9 & 8.3 & 5.7 \\
\hline 8 & 7.9 & 5.2 & 3.9 & 3.2 & 4.5 & 8.9 \\
\hline
\end{tabular}


using dummy variables which accounted for interindividual variation in cerebral blood flow. The estimated regression coefficient thus depended only on the intra-individual variation in cerebral blood flow and was used to estimate the relation between it and $\mathrm{PaCO}_{2}$. The log-linear relation implies that the calculated cerebral blood flow response is percentual (the antilogarithm of the regression coefficient is equal to the cerebral blood flow reactivity). The correlation between cerebral blood flow and MAP was also tested this way.

In addition, analysis of variance and the Student-Newman-Keuls test were used to ascertain if there was a systematic difference in $\mathrm{PaCO}_{2}$ before and after L-NAME, and whether there were differences in other physiological parameters between measurements. The SPSSPC statistical programme (SPSS Inc., Chicago, Illinois, USA) was used for calculations, and the level of significance set at 0.05 .

\section{Results}

The values recorded during cerebral blood flow measurements, before and after the administration of L-NAME, are given in table 1. There was no significant difference in the mean values of core temperature, arterial blood gas analyses, base excess, haemoglobin or glucose between measurements. The $\mathrm{PaCO}_{2}$ of individual subjects during each of the six measurements is shown in table 2. End-tidal $\mathrm{PCO}_{2}$ fluctuation during cerebral blood flow measurements was median $0.2 \mathrm{kPa}$ (range $0-0.3$ ). Following $\mathrm{PaCO}_{2}$ manipulation MAP changed median $+3 \mathrm{~mm} \mathrm{Hg}$ (range 2-5). After L-NAME, MAP increased from $65 \mathrm{~mm} \mathrm{Hg}$ (SD 8) to $75 \mathrm{~mm} \mathrm{Hg}$ (SD 9), mean change 10 $\mathrm{mm} \mathrm{Hg}(95 \% \mathrm{CI} 5$ to 11$)(\mathrm{P}<0.05)$. This rise was maintained until the administration of L-arginine, when MAP decreased from $75 \mathrm{~mm}$ $\mathrm{Hg}$ (SD 8) to $55 \mathrm{~mm} \mathrm{Hg}$ (SD 6), mean change $-18 \mathrm{~mm} \mathrm{Hg}$ (95\% CI -10 to -25$)(\mathrm{P}<0.05)$.

The mean (SD) values of cerebral blood flow were $49.4(16.5) \mathrm{ml} / 100 \mathrm{~g} /$ minute before and $46.1(21.5) \mathrm{ml} / 100 \mathrm{~g} /$ minute after administration of L-NAME, and were not significantly different. However, when values were adjusted for differences in $\mathrm{PaCO}_{2}$ (see below), L-NAME resulted in a significant decrease in cerebral blood flow of $14.0 \% \quad(95 \%$ CI 1.9-27.4) $(\mathrm{P}<0.05)$.

The relation between cerebral blood flow and $\mathrm{PaCO}_{2}$ for all measurements for each animal before and after the administration of L-NAME is shown in figs 1 and 2. The overall $\mathrm{CBF}-\mathrm{CO}_{2}$ reactivity for all six measurements was $16.2 \% / \mathrm{kPa}(95 \%$ CI $12.0-20.5)$. CBF$\mathrm{CO}_{2}$ reactivity was $18.4 \% / \mathrm{kPa}(95 \%$ CI 14.1-22.2) before L-NAME and $15.2 \% / \mathrm{kPa}$ (95\% CI 11.1-19.3) after L-NAME; the difference between the $\mathrm{CBF}-\mathrm{CO}_{2}$ reactivities was $3.2 \% / \mathrm{kPa}(95 \% \mathrm{CI}-0.4-6.8)$ : these values were not significantly different from each other.

The relation between cerebral blood flow and MAP was $0.8 \% \mathrm{~mm} \mathrm{Hg}(95 \% \mathrm{CI}-0.5-2.1)$ before, and $0.7 \% \mathrm{~mm} \mathrm{Hg}(95 \% \mathrm{CI}-0.4-1.7)$

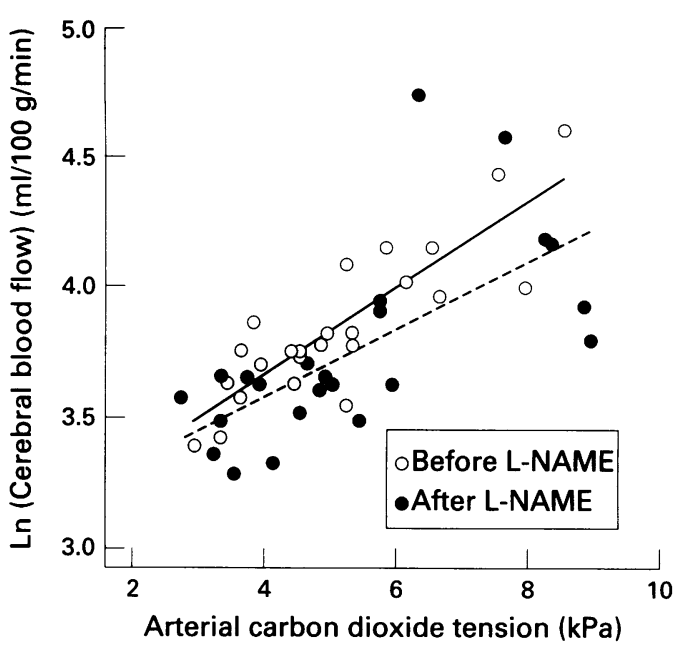

Figure 1 Relation between cerebral blood flow and $\mathrm{PaCO}_{2}$ for all measurements for each animal. Data points before and after L-NAME are shown. Natural log transformed cerebral blood flow values (Ln cerebral blood flow) are shown. $\mathrm{CBF}-\mathrm{CO}_{2}$ reactivity represented by the slope of the regression line before $L-N A M E$ (solid line) was not significantly different after L-NAME (dotted line).

after administration of L-NAME, which were not significantly different from zero.

\section{Discussion}

Cerebral blood flow measurement using the ${ }^{133}$ Xenon clearance technique has been validated against other techniques in experimental animals and in newborn infants. ${ }^{17-19}$ The technique assumes that cerebral blood flow remains constant during a measurement; in this study this was believed to be the case as end-tidal $\mathrm{PCO}_{2}$ and $\mathrm{FIO}_{2}$ remained stable during measurements. A cerebral blood flow greater than $120 \mathrm{ml} / 100 \mathrm{~g} /$ minute may prevent complete equilibration of ${ }^{133}$ Xenon between blood and brain, ${ }^{20}$ but such values were not seen in the study. Calculation of absolute cerebral blood flow values requires knowledge about the blood to brain partition coefficients. As these values are unknown for newborn piglets, the values derived from adult humans were used. Nevertheless, although the absolute values need to be interpreted with caution, the direction and proportion of any change should be accurate. The cerebral blood flow values in our study are comparable with those obtained using other techniques. ${ }^{21} 22$

L-NAME was administered in concentrations shown previously to have close to a maximal effect on MAP and CBV. Administration of L-arginine completely reversed the effects on MAP, demonstrating the specificity of the observed effect. There was no significant relation between cerebral blood flow and MAP during the study. Even though cerebral blood flow pressure autoregulation was not specifically investigated, our data do not indicate a role for NO in cerebral blood flow pressure autoregulation during acute rises in MAP.

Administration of L-NAME caused a small decrease in cerebral blood flow. These results are consistent with our previous experiments in newborn piglets, and in other studies in mature animals, in showing that a tonic release of NO participates in the maintenance of basal CBF. ${ }^{12}{ }^{23}{ }^{24}$ The proportional change in cere- 


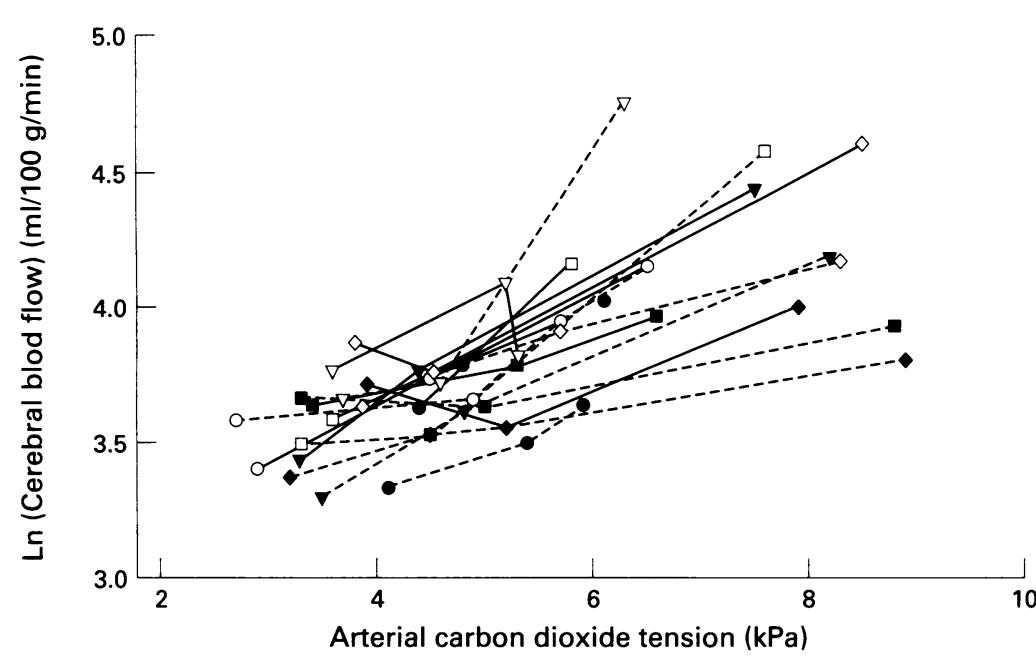

Figure 2 Relation between cerebral blood flow and $\mathrm{PaCO}_{2}$ for all measurements for each animal. Each animal is represented by a different symbol. Measurements before (solid line) and after (dotted line) L-NAME are shown. Natural log transformed cerebral blood flow values (Ln cerebral blood flow) are shown.

bral blood flow is not dissimilar to the change previously noted in CBV, and suggests that tonic NO secretion has some effect on the calibre of resistance vessels, modulating rate, and distribution of cerebral perfusion in newborn animals. However, the fall in cerebral blood flow induced by L-NAME is no greater than would normally occur with a $0.5-1.0 \mathrm{kPa}$ fall in $\mathrm{PaCO}_{2}$. This is consistent with suggestions that although constitutive NO secretion may control the distribution of flow, perhaps matching perfusion to metabolism, it is not an important mediator of the generalised alterations in vascular tone which determine bulk flow. ${ }^{25}$

Most reports have shown that NO participates in $\mathrm{CBF}-\mathrm{CO}_{2}$ reactivity in adult rats, cats, dogs and rabbits, and that inhibition of this effect by $\mathrm{L}$-arginine analogues is stereospecific, dose related, and reversed by co-application of L-arginine. ${ }^{26-29}$ Although a few studies offer conflicting results, ${ }^{30-32}$ the weight of evidence suggests that in adult animals $\mathrm{NO}$ is a mediator of $\mathrm{CBF}-\mathrm{CO}_{2}$ reactivity. In contrast to these studies, but consistent with our previous experiments in newborn piglets, we found no evidence to suggest that NO was involved in $\mathrm{CBF}-\mathrm{CO}_{2}$ reactivity in the newborn piglet.

This may be a specific maturational effect. Armstead et al have shown that the vascular responses of piglets change with age: acetylcholine, which elicits NO mediated vasodilation, produced NO dependent pial arteriolar vasodilation in juvenile pigs but not in newborn pigs. ${ }^{33}$ In newborn pigs acetylcholine produced pial arterial vasoconstriction dependent on stimulation of the prostaglandin $\mathrm{H} 2 /$ thromboxane A2 receptor. ${ }^{10}$ Greenberg et al suggested that in 1 to 2 week old piglets NOS inhibition led to greater declines in cerebral blood flow. ${ }^{22}$ Wyatt et al have also shown that cerebral reactivity to carbon dioxide increases during 26-40 weeks of gestation, demonstrating differences related to brain development. ${ }^{34}$

The influence of midazolam and isoflurane need to be considered as they have effects on the cerebral circulation. ${ }^{35}$ Following premedication with midazolam, at least 90 min- utes elapsed before the experiments were performed, thus reducing the possibility of drug related effects. Isoflurane was used as it is a clinically relevant anaesthetic and its use is associated with haemodynamic stability. Both drugs have also been shown to maintain CBF$\mathrm{CO}_{2}$ reactivity. ${ }^{35} 36$

These data suggest the testable hypothesis: that participation of the L-arginine NO system in the generalised and co-ordinated control of cerebral blood flow required to modulate $\mathrm{CBF}-\mathrm{CO}_{2}$ reactivity, develops after birth. Similar postnatal developments in NO responsiveness in the pulmonary vasculature have been described in piglets. ${ }^{37-39}$

We thank Mr M K Chakrabarti for valuable assistance. J Patel is supported by the British Heart Foundation.

O Pryds is supported by the Dagmar Marshall Foundation, Ville Heise Foundation, and the Beckett Foundation.

1 Pape KE, Wigglesworth JS. Haemorrhage, ischaemia and the perinatal brain. London: Spastics International Medical publications, 1979.

2 Lou HC, Skov H, Pedersen H. Low cerebral blood flow: risk factor in the neonate. F Pediatr 1979;95:606-9.

3 Iadecola C, Pelligrino DA, Moskowitz MA, Lassen NA Nitric oxide synthase inhibition and cerebrovascular regulation. F Cereb Blood Flow Metab 1994;14:175-92.

4 Faraci FM, Brian JE. Nitric oxide and the cerebral circulation. Stroke 1994;25:692-703.

5 McPherson RW, Kirsch JR, Ghaly RF, Traystman RJ. Effect of nitric oxide synthase inhibition on the cerebral vascular
response to hypercapnia in primates. Stroke 1995; response

6 Iadecola C, Xiaohong XU. Nitro-L-arginine attenuates hypercapnic cerebrovasodilation without affecting cerebra metabolism. Am f Physiol 1994;266:R518-25.

7 Malinski T, Bailey F, Zhang ZG, Chopp M. Nitric oxide measured by a porphyinic microsensor in rat brain after transient middle cerebral artery occlusion. 7 Cereb Blood Flow Metab 1993;13:355-8.

8 Carreau A, Duval D, Poignet H, Scatton B, Vige X, Nowicki JP. Neuroprotective efficacy of $N \omega$-nitro-L-arginine after focal cerebral ischaemia in the mouse and inhibition of cortical nitric oxide synthase. Eur $\mathcal{F}$ Pharmacol 1994 25:241-9.

9 Nishikawa T, Kirsch JR, Koehler RC, Miyabe M, Traystman RJ. Nitric oxide synthase reduces caudate injury followin transient focal ischaemia in cats. Stroke 1994;25:877-85.

10 Armstead WM, Mirro R, Busija DW, Leffler CWJ. Permissive role of prostanoids in acetylcholine-induced cerebral
vasoconstriction. F Pharmacol Exp Ther 1989;251:101219.

11 Meadow W, Rudinsky B, Anthony B, Lozon M, Randle C Hipps R. The role of prostaglandins and endotheliumderived relaxation factor in the regulation of cerebra blood flow and cerebral oxygen utilization in the piglet: operationalizing the concept of an essential circulation. Pediatr Res 1994;35:649-56.

12 Takei Y, Edwards AD, Lorek A, Peebles DM, Belai A, Cope-M, et al. Effects of N-omega-nitro-L-arginine methyl ester on the cerebral circulation of newborn piglets quantified in vivo by near-infrared spectroscopy. Pediatr quantified in vivo

13 Greisen G, Pryds O. Intravenous ${ }^{133}$ Xenon clearance in preterm neonates with respiratory distress. Internal validation of $\mathrm{CBF}$ as a measure of global cerebral blood flow. Scand $\mathcal{F}$ Clin Lab Invest 1988;48:637-78.

14 Mallett BL, Veall N. The partition of trace amounts of Xenon between human blood and brain tissue at $37^{\circ} \mathrm{C}$ Phys Med Biol 1965;10:375-80.

15 Obrist WD, Wilkinson WE. The non-invasive Xe-133 method. Evaluation of CBF indices. In: Bes A, Geraud G, eds. Cerebral circulation and neurotransmitters. Amsterdam: Excerpta Medica, 1980:119-24.

16 Pryds O, Schneider S. Aminophylline reduces cerebral blood flow in stable, preterm infants without affecting the visual evoked potential. Eur $\mathcal{F}$ Pediatr 1991;150:366-9.

17 Marcus ML, Bischof CJ, Heistad DD. Comparison of microsphere and Xenon-133 clearance method in measuring skeletal muscle and cerebral blood flow. Circ Res 1981; 48:748-61.

18 Skov L, Pryds O, Greisen G. Estimating cerebral blood flow in newborn infants: comparison of near infrared spectroscopy and 133Xe clearance. Pediatr Res 1991;30:570-3.

19 Bucher HU, Edwards AD, Lipp AE, Duc G. Comparision between near infrared spectroscopy and 133-Xenon clearance for estimation of cerebral blood flow in critically ill ance for estimation of cerebral blood flow

20 Tomita M, Gotoh F. Local cerebral blood flow values as estimated with diffusible tracers: validity of assumptions in normal and ischemic tissue. $\mathcal{f}$ Cereb Blood Flow Metab 1981;1:403-11. 
21 Wootton R, Flecknall PA, John M. Accurate measurement of cerebral metabolism in the conscious, unrestrained neonatal piglet. Biol Neonate 1982;41:209-20.

22 Greenberg RS, Helfaer MA, Kirsch JR, Moore LE, Traystman RJ. Nitric oxide synthase inhibition with NG-monomethyl-L-arginine reversibly decreases cerebral blood flow in piglets. Crit Care Med 1994;22:384-92.

23 Kovach AG, Szabo C, Benyo Z, Csaki C, Greenberg JH, Reivich M. Effects of NG-nitro-L-arginine and L-arginine on regional cerebral blood flow in the cat. $₹$ Physiol 1992; 449:183-96.

24 Tanaka K, Gotoh F, Gomi S, Takashima S, Mihara B, Shira $\mathrm{T}$, et al. Inhibition of nitric oxide synthesis induces significant reduction in local cerebral blood flow in the rat. Neurosci Lett 1991;127:129-32.

25 Griffith TM, Edwards DH, Davies RL, Harrison TJ, Evan KT. EDRF coordinates the behaviour of vascular resistance vessels. Nature 1987;329:442-5.

26 Pelligrino DA, Koenig HM, Albrecht RF. Nitric oxide synthesis and regional cerebral blood flow responses to hypercapnia and hypoxia in the rat. $\mathcal{F}$ Cereb Blood Flow Metab 1993;13:80-7.

27 Sandor P, Komjati K, Reivich M, Nyary I. Major role of nitric oxide in the mediation of regional $\mathrm{CO} 2$ responsiveness of the cerebral and spinal cord vessels of the cat. $f$ ness of the cerebral and spinal cord vess

28 Saito S, Wilson DA, Hanley DF, Traystman RJ. Nitric oxide modulates cerebral vessel tone and depresses cerebrovascular resistance changes to carbon dioxide in anaesthetised dogs. F Cereb Blood Flow Metab 1993;13:S153.

29 Faraci FM, Breese KR, Heistad DD. Cerebral vasodilation during hypercapnia: role of glibenclamide-sensitive potassium channels and nitric oxide. Stroke 1994;25:1679-83.

30 Adachi T, Inanami O, Sato A. Nitric oxide (NO) is involved in increased cerebral cortical blood flow following stimulain increased cerebral cortical blood flow following stimulation of the nucleus basalis of
31 Dieguez G, Garcia JL, Fernandez N, Garcia Villalon AL, Monge $L$, Gomez B. Role of NO in goat basal cerebral circulation and after vasodilatation to hypercapnia or brief ischemias. Am F Physiol 1993;265:R1410-15.

32 Sokoloff L, Kennedy C, Adachi K, Wang S, Takahashi S, Melzer P. Effects of nitric oxide synthase on resting cerebral blood flow and on changes induced by hypercapnia or local functional activity. In: Krieglstein J Oberpichler-Schwenk $\mathbf{H}$, eds. Pharmacology of cerebral ischemia. Stuttgart: Wissenschaftliche Verlagsgesellschaft ischemia. Stuttga

33 Armstead WM, Zuckerman SL, Shibata M, Parfenova H Leffler CW. Different pial arteriolar responses to acetylcholine in the newborn and juvenile pig. F Cereb Blood Flow Metab 1994;14:1088-95.

34 Wyatt JS, Edwards AD, Cope M, Delpy DT, McCormick DC, Potter A, et al. Response of cerebral blood volume to changes in arterial carbon dioxide tension in preterm and term infants. Pediatr Res 1991;29:553-7.

35 Kumano H, Furuya H, Yomosa H, Nagahata T, Okuda T, Sakaki T. Response of pial vessel diameter and regiona cerebral blood flow to $\mathrm{CO} 2$ during midazolam administration in cats. Acta Anaesthesiol Scand 1994;38:729-33.

$36 \mathrm{McPherson}$ RW, Briar JE, Traystman RJ. Cerebrovascula responsiveness to carbon dioxide in dogs with $1.4 \%$ and $2.8 \%$ isoflurane. Anesthesiology 1989;70:843-50.

37 Zellets TM, Vanhoutte PM. Endothelium-dependent relaxation of piglet pulmonary arteries augment with maturation. Pediatr Res 1991;30:176-80.

38 Liu SF, Hislop AA, Haworth SG, Barnes PJ. Developmental changes in endothelium-dependent pulmonary vasodilation in pigs. $B r \mathcal{f}$ Pharmacol 1992;106:324-30.

39 Levy M, Tulloh RM, Hiroyoshi K, Stuart-Smith K Haworth SG. Maturation of the contractile response and its endothelial modulation in newborn porcine intrapulmonary arteries. Pediatr Res 1995;38:25-9. 